\title{
Article
}

\section{Validating Aerosol Optical Depth Estimation Methods Using the National Institute of Environmental Research Operational Numerical Forecast Model}

\author{
Hye-Jin Kim ${ }^{1}$, Uju Shin ${ }^{1}$, Won Jun Choi ${ }^{2}{ }^{\mathbb{D}}$, Ja-Ho Koo $\left.{ }^{1}{ }^{(}\right)$, Chang H. Jung ${ }^{3} \mathbb{D}$, Ki-Pyo Nam ${ }^{2}$ \\ and Sang-Hun Park ${ }^{1, *}$
}

check for

updates

Citation: Kim, H.-J.; Shin, U.; Choi,

W.J.; Koo, J.-H.; Jung, C.H.; Nam,

K.-P.; Park, S.-H. Validating Aerosol Optical Depth Estimation Methods

Using the National Institute of

Environmental Research Operational

Numerical Forecast Model. Appl. Sci. 2022, 12, 2556. https://doi.org/

10.3390/app12052556

Academic Editor:

Kyung-Hwan Kwak

Received: 19 January 2022

Accepted: 24 February 2022

Published: 28 February 2022

Publisher's Note: MDPI stays neutral with regard to jurisdictional claims in published maps and institutional affiliations.

Copyright: (C) 2022 by the authors. Licensee MDPI, Basel, Switzerland. This article is an open access article distributed under the terms and conditions of the Creative Commons Attribution (CC BY) license (https:// creativecommons.org/licenses/by/ $4.0 /)$.
1 Department of Atmospheric Sciences, Yonsei University, Seoul 03722, Korea; haejin0828@yonsei.ac.kr (H.-J.K.); shinuju@yonsei.ac.kr (U.S.); zach45@yonsei.ac.kr (J.-H.K.)

2 Air Quality Forecasting Center, National Institute of Environmental Research, Incheon 22689, Korea; choiwj@me.go.kr (W.J.C.); kipyonam@korea.kr (K.-P.N.)

3 Department of Health Management, Kyung-in Women's University, Incheon 21041, Korea; jch@kiwu.ac.kr

* Correspondence: pshun@yonsei.ac.kr

\begin{abstract}
Currently, significant efforts are being made to enhance the performance of the National Institute of Environmental Research (NIER) operational model. However, the model performance concerning Aerosol Optical Depth (AOD) estimation remains uninvestigated. In this study, three different estimation methods for AOD were implemented using the NIER operational model and validated with satellite and ground observations. In the widely used Interagency Monitoring of Protected Visual Environments (IMPROVE) method, AOD exponentially increases with relative humidity owing to a hygroscopic growth factor. However, alternative methods show better performance, since AOD estimation considers the size dependency of aerosol particles and is not sensitive to high relative humidity, which reduces the high AOD in areas with large cloud fractions. Although some R values are significantly low, especially for a single observational comparison and small numerical domain analysis, one of the alternative estimation methods achieves the best performance for diagnosing $\mathrm{AOD}$ in the East Asia region.
\end{abstract}

Keywords: aerosol optical depth (AOD); weather research and forecasting community multi-scale air-quality (WRF-CMAQ); hygroscopic growth factor

\section{Introduction}

Atmospheric aerosols influence the Earth's radiation balance by absorbing or scattering radiation and induce climate change [1]. As a representing parameter of atmospheric aerosol, aerosol optical depth (AOD), defined as the extinction of solar radiation caused by aerosol and integrated into the whole atmospheric column, is a fundamental optical property parameter and is widely used [2] in the scientific community. Generally, AOD is measured by satellite and ground-based remote sensing. Since AOD strongly correlates with air pollutant variables such as $\mathrm{PM}_{2.5}$ and $\mathrm{PM}_{10}$, it can act as an efficient parameter for estimating air pollutants.

AOD can be expressed as a function of several aerosol related factors, such as aerosol mass concentration, composition, size distribution, and meteorological parameters. Among the many factors which influence the calculation of AOD, hygroscopicity is one of the most uncertain factors [3]. The hygroscopic growth of aerosols is closely related to relative humidity (RH) and influence the physico-chemical characteristics of aerosol. For instance, different aerosol sources, types, and chemical components cause aerosol hygroscopicity to vary with space and time and affect the aerosol optical properties, such as AOD, due to increasing water uptake by increasingly hydrophilic compositions [4].

The Korean Ministry of Environment (KME) and the National Institute of Environmental Research (NIER) produce two-dimensional AOD data based on cutting-edge technology 
from satellite data [5-7], but there are still limitations in stably identifying concentrations of air pollutants. For example, spatial and temporal resolutions may not be sufficient for operational needs, and many satellite images suffer from a high cloud fraction or high surface reflectance. In terms of high cloud fraction, baroclinic waves are most active in the mid-latitude spring or wintertime when severe pollutant episodes are frequent. Hence, complementary methods using numerical or statistical models to address missing data are essential.

The simulation and forecasting of air quality using numerical models are common for obtaining accurate and continuous information on air pollution. Models' performances decrease with forecast or simulated time, and significant efforts are being made to increase the accuracy or extend predictability. These methods can be categorized into two approaches: (1) decreasing the uncertainty of model complexity, such as emissions, boundary conditions, and parameterization for atmospheric processes (e.g., [8-10]); and (2) increasing the accuracy of initial conditions using data assimilation techniques with ground and satellite observations (e.g., [11-14]). However, while issues remain, several studies have accurately estimated AOD from air-quality models.

This study aimed to analyze the performance of several AOD-estimation methods from the operational air quality model of the NIER. Although significant efforts are being made to enhance the performance of NIER's operational model, in this study, we focused on the ability and performance of AOD estimation based on past forecasting results. If the missing values of satellite observations are related to a high cloud fraction, they should have a significant dependency on the cloud hygroscopic growth factor in that region. Herein, the effects of $f(\mathrm{RH})$ on aerosol mass concentration are discussed and different parametrization methods for $\mathrm{f}(\mathrm{RH})$ are compared with conventional methods. The results of this study reveal fundamental problems and provide suggested strategies for improved AOD estimation when using the operational WRF-CMAQ model in Korea.

The Interagency Monitoring of Protected Visual Environments (IMPROVE) estimation method (or Malm's reconstructed method) [15] is widely used in the Weather Research and Forecasting (WRF)-Community Multi-Scale Air-quality (CMAQ) community. One of the main limitations of Malm's reconstructed method is that it cannot consider the sizedependent function of relative humidity $(\mathrm{f}(\mathrm{RH}))$, which is an important aspect of aerosol hygroscopicity $[3,16]$. Most of the previous studies have not considered the size-dependent effects due to the complexity in reflecting polydispersity implying that $f(R H)$ is to be assumed constant regardless of the size [16]. However, many theoretical and empirical studies have suggested that individual chemical substances should be specifically assessed based on their size $[3,17-20]$. From a theoretical point of view, $f(R H)$ should be recalculated using a thermodynamic model and the Mie theory for each size distribution. Thus, it is important to understand the size dependency of $f(R H)$, and it is necessary to investigate whether it has a serious sensitivity or uncertainty with respect to aerosol hygroscopic growth factors upon considering size effects.

The remainder of this paper is organized as follows. In Section 2, the operational model and data are introduced, and the estimated AOD algorithms are summarized. A qualitative comparison between satellite images and estimated AODs is presented in Section 3; in addition, a more quantitative analysis focused on the Seoul metropolitan area is presented along with detailed statistical results for the entire domain of the NIER operational model. Section 4 summarizes the results of the study.

\section{Data and Methods}

\subsection{Data}

To evaluate AOD calculation from an air-quality model, we verified the operational forecast results from NIER from March 2016 to February 2017, including the period of the KORUS-AQ (International Cooperative Air Quality Field Study in Korea) campaign (https: / / espo.nasa.gov/home/korus-aq/content/KORUS-AQ, accessed on 17 February 2022). 


\subsubsection{Description of the NIER Operational Forecast Model}

The NIER operates an air quality forecast system using the CMAQ model [21,22] along with meteorological inputs provided by the Weather Research Forecasting (WRF) model ([23]). An operational forecast system has been introduced [24,25] and the model configurations are summarized in Table 1. CMAQ v4.7 was used to estimate the concentrations of atmospheric chemical species. The chemical mechanism in the CMAQ was the Statewide Air Pollution Research Center, Version 99 (SAPRC99; [26]), and the 5th generation CMAQ aerosol module (AERO5) was used for aerosol simulation. Air pollutant emissions include both anthropogenic and natural emissions. MIX 2010 [27] and the Clean Air Policy Support System (CAPSS) was used to measure anthropogenic emissions. Anthropogenic emissions were allocated spatiotemporally using Sparse Matric Operator Kernel Emissions (SMOKE; [28]) and then utilized in the air quality model. Furthermore, biogenic emissions were utilized based on the Model of Emission of Gases and Aerosols from Nature (MEGAN) version 2.04. [29,30].

Table 1. Configuration of the National Institute of Environmental Research (NIER) operational air quality forecast system.

\begin{tabular}{cc}
\hline Configuration & Description \\
\hline Model version & WRF v3.3 \\
Microphysics & WRF Single-Moment 3-class scheme \\
Cumulus convection & Kain-Fritsch \\
Longwave radiation & RRTM scheme \\
Shortwave radiation & Goddard shortwave \\
Land surface & NOAH [31] \\
PBL scheme & YSU [32] \\
Model version & CMAQ v4.7 \\
Chemical mechanism & SAPRC99 \\
Aerosol module & AERO5 \\
Chemical solver & EBI \\
Advection scheme & YAMO \\
Horizontal diffusion & Multiscale \\
Vertical diffusion & Eddy \\
Cloud scheme & ACM \\
\hline
\end{tabular}

The spatial resolutions of the WRF-CMAQ model operated by NIER are $27 \mathrm{~km}$ (D01), $9 \mathrm{~km}$ (D02), and $3 \mathrm{~km}$ (D03), as shown in Figure 1a. The models forecast $76 \mathrm{~h}$ from 03 UTC every day. In this study, we analyzed AOD concentrations from the 27 and $9 \mathrm{~km}$ grid domains for East Asia and the Korean Peninsula, respectively.

\subsubsection{Observational Data}

In this study, we used Geostationary Ocean Color Imager (GOCI) and Aerosol Robotic Network (AERONET) data to validate the horizontal distribution of AOD. The GOCI provides hourly daylight spectral images eight times a day from 00:30 to 07:30 UTC over East Asia; these data cover a $2500 \times 2500 \mathrm{~km}$ region centered on $36^{\circ} \mathrm{N}$ and $130^{\circ} \mathrm{E}$ in eight spectral channels $(412,443,490,555,660,680,745$, and $865 \mathrm{~nm}$, [7]). AERONET is a groundbased sun photometer network distributed worldwide that provides the optical properties of aerosols at several wavelengths between 340 and $1640 \mathrm{~nm}$ [33]. In this study, we use level2 set of AERONET data from (http: / / aeronet.gsfc.nasa.gov, accessed on 17 February 2022). The estimated AOD from D01 was examined using 15 AERONET datasets over East Asia, as shown in Figure 1a. D02 was examined using six AERONET datasets over the Korean Peninsula (Korea) region, as shown in Figure 1a. The Yonsei-YSU station, located in the Seoul Urban Area of South Korea, was selected to compare the temporal variation of the estimated AOD, because it had the smallest number of missing values during our research period. 


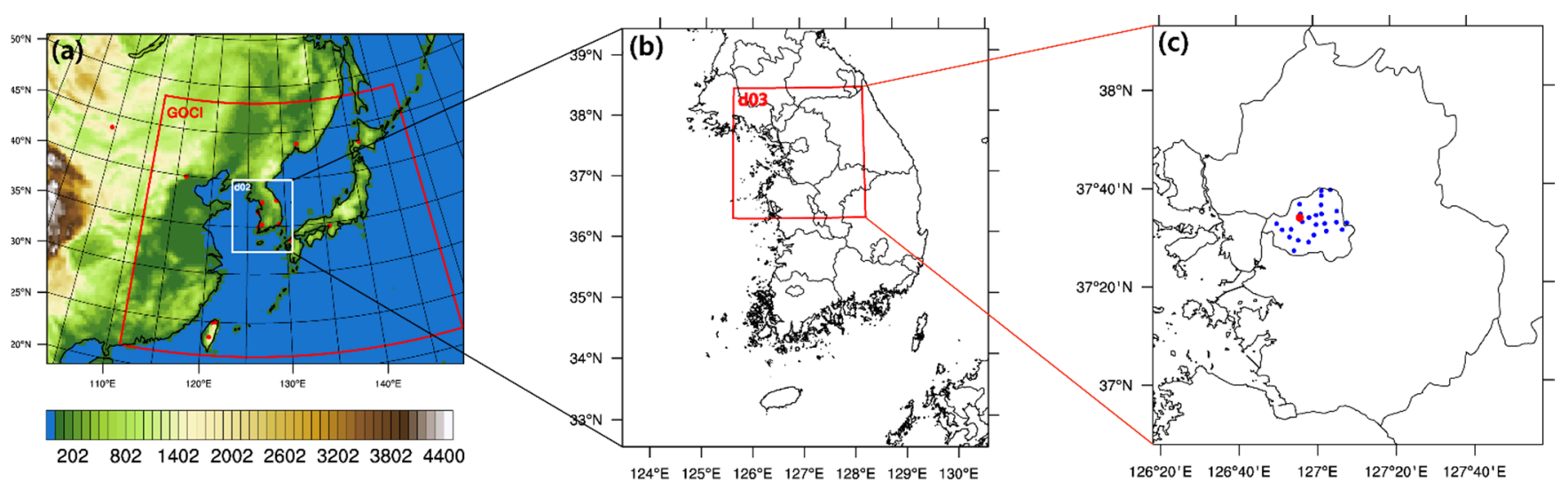

Figure 1. (a) Domain of the National Institute of Environmental Research (NIER) operational forecast model. Shadings represent the terrain height $(\mathrm{m})$. The red box and red-colored dots represent Geostationary Ocean Color Imager (GOCI) coverage and the locations of Aerosol Robotic Network (AERONET) sites in East Asia. (b) Domain 2 and (c) domain 3 of NIER operational forecast system are shown with $\mathrm{PM}_{2.5}$ observation sites (blue dots) of Air Korea in the Seoul metropolitan area and Yonsei AERONET site (red dot).

\subsection{Estimation Methods for $A O D$}

\subsubsection{IMPROVE and Its Uncertainty}

The Malm [15] Interagency Monitoring of Protected Visual Environments (IMPROVE) equation is a commonly used WRF-CMAQ diagnosis approach [15,34-36]. Two aerosol extinction coefficients are critical for diagnosing AOD [15], as follows:

$$
\mathrm{AOD}=\sum_{i=1}^{N}\left(\sigma_{s p}+\sigma_{a p}\right)_{i} \Delta Z_{i}
$$

where $N$ is the number of vertical layers in the numerical model, $\Delta Z_{i}$ is the thickness of each layer, and $\sigma_{s p}$ and $\sigma_{a p}$ are the aerosol extinction coefficients of scattering and absorption by particles, respectively. In Equation (1), $\sigma_{s p}$ and $\sigma_{a p}$ are calculated using the following relation:

$$
\begin{gathered}
\sigma_{s p}=0.003 \times \mathrm{f}(\mathrm{RH}) \times\left[\mathrm{NH}_{4}^{+}+\mathrm{SO}_{4}^{-}+\mathrm{NO}_{3}^{-}\right]+0.004 \times[\text { Organic Mass }]+0.001 \times[\text { Fine soil }] \\
+0.0006 \times[\text { Coasre Mass }] \\
\sigma_{a p}=0.01 \times[\text { Light Absorbing Carbon }]
\end{gathered}
$$

The unit of air pollutants in is $\mathrm{mg} \mathrm{m}^{-3}$, and the unit of each coefficient $(0.003,0.004$, $0.001,0.0006$, and 0.01$)$ is $\mathrm{m}^{2} \mathrm{mg}^{-1} ; \mathrm{f}(\mathrm{RH})$ is a function that depends on relative humidity and is calculated as follows:

$$
\mathrm{f}(\mathrm{RH})=b_{0}+b_{1}\left(\frac{1}{1-\mathrm{RH}}\right)+b_{2}\left(\frac{1}{1-\mathrm{RH}}\right)^{2}
$$

where $b_{0}, b_{1}$, and $b_{2}$ are correlation parameters that vary seasonally, as listed in Table 2 . It should be noted that $\mathrm{f}(\mathrm{RH})$ applies to the inorganic aerosol $\left(\left[\mathrm{NH}_{4}^{+}+\mathrm{SO}_{4}^{-}+\mathrm{NO}_{3}^{-}\right]\right)$ only. According to previous studies, a non-negligible fraction of organic aerosol is watersoluble [37,38]. Moreover, a substantial fraction of water-soluble organic aerosol is known to be composed of humic-like substances (HULIS), associated with light-absorbing brown carbon aerosol. However, lot of complexities and uncertainties exist in the characterization of organic aerosol. In this study, we assumed that organic aerosol is non-hygroscopic and non-absorbing aerosol [39]. A drawback of Equation (4) is that it is unable to consider the size dependence of $f(\mathrm{RH})$ [40]. A practical issue in Equation (4) is the formulation of the denominator using relative humidity. A problem arises when the value of $f(R H)$ becomes 
unrealistically large (when RH approaches 1). Therefore, the maximum RH value is limited. The uncertainties and sensitivities are shown in Figure 2. Figure 2 displays the horizontal distribution of GOCI AOD at 01:00 UTC 24 May 2016, along with estimated AODs from the NIER operational model following Equations (2)-(4) with maximum RH values of $93 \%$, $96 \%$, and $98 \%$ to avoid infinite values from Equation (4). GOCI AOD does not appropriately represent the AOD value in the area with clouds (Figure 2a); the estimated AODs from the operational model show a large sensitivity to cloud area depending on the maximum $\mathrm{RH}$ from Equation (4) (Figure $2 \mathrm{~b}-\mathrm{d}$ ). In the broad cloud region, estimated AODs more than doubled as the value of the maximum RH increases from $93 \%$ to $98 \%$.

Table 2. Seasonal parameters of $b_{0}, b_{1}$, and $b_{2}$ in Equation (4).

\begin{tabular}{cccc}
\hline & $\boldsymbol{b}_{\mathbf{0}}$ & $\boldsymbol{b}_{\mathbf{1}}$ & $\boldsymbol{b}_{\mathbf{2}}$ \\
\hline Spring & -0.01097 & 0.78095 & 0.08015 \\
Summer & -0.18614 & 0.99211 & - \\
Fall & -0.24812 & 1.01865 & 0.01074 \\
Winter & 0.34603 & 0.81984 & - \\
Annual & 0.33713 & 0.58601 & 0.09164 \\
\hline
\end{tabular}
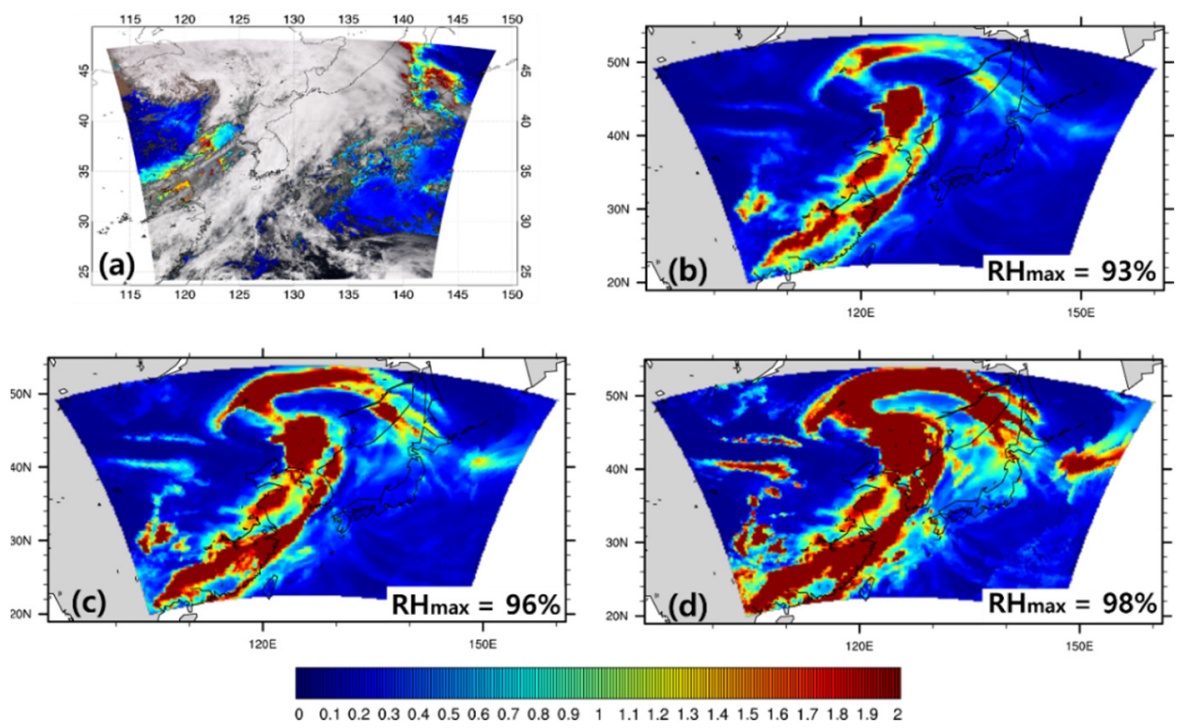

Figure 2. (a) Observed aerosol optical depth (AOD) obtained from the geostationary ocean color imager (GOCI) satellite at 01:00 UTC on 24 May 2016. Estimated AOD calculated using the Interagency Monitoring of PROtected Visual Environments (IMPROVE) method [15] with maximum relative humidity (RH) values of (b) $93 \%$, (c) $96 \%$, and (d) $98 \%$.

\subsubsection{Other Formulations for Estimating AOD from WRF-CMAQ}

Hygroscopic growth factors are determined by relative humidity; as such, formulations such as Equation (4) are essential for estimating the AOD algorithm. We applied two alternative methods to remove the uncertainty from the IMPROVE method [15]. First, we replaced Equation (4) following the method of Kiehl [41]:

$$
f(R H)=\exp \left(-1-\frac{0.6}{R H-1.2}-\frac{0.75}{R H-1.5}\right)
$$

Equation (5) was obtained by solving the Köhler equation to determine the equilibrium radius of dry sulfate aerosol particles at a given relative humidity and fitting their size distribution with a lognormal size distribution [41]. In most simulations, there is no case where supersaturation exists for $\mathrm{RH} \geq 1.2$; thus, we did not set an upper limit for $\mathrm{RH}$ in Equation (5). 
Second, we applied the Pitchford method [16], in which AOD is estimated from the empirical reconstructed mass-extinction as:

$$
\mathrm{AOD}=\sum_{i=1}^{N}\left(b_{\text {ext }}\right)_{i} \Delta \mathrm{Z}_{i}
$$

where $N$ is the number of vertical layers in the numerical model, $\Delta Z_{i}$ is the thickness of each layer, and $b_{\text {ext }}$ is light extinction due to scattering and absorption by particles. In Equation $(6), b_{\text {ext }}$ is calculated using the relation:

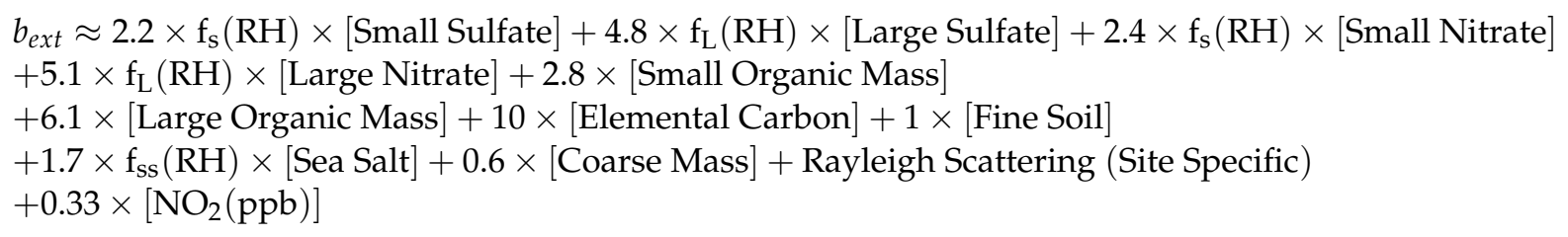

The unit of air pollutants is $\mathrm{mg} \mathrm{m}^{-3}$, and the unit of each coefficient $(2.2,4.8,2.4,5.1$, $2.8,6.1,10,1,1.7,0.6$, and 0.33$)$ is expressed as $\mathrm{m}^{2} \mathrm{mg}^{-1} ; \mathrm{f}_{\mathrm{s}}(\mathrm{RH}), \mathrm{f}_{\mathrm{L}}(\mathrm{RH})$, and $\mathrm{f}_{\mathrm{sS}}(\mathrm{RH})$ are the small size, large size, and sea salt hygroscopic growth factor functions, respectively. Equations (6) and (7) consider the effects of sea salt on extinction over the ocean and subdivide hygroscopic growth factors according to particle size [28], unlike the IMPROVE algorithm of Malm [15]. They use an organized look-up table (see Tables A1 and A2 in Appendix A) for building $\mathrm{f}_{\mathrm{s}}(\mathrm{RH}), \mathrm{f}_{\mathrm{L}}(\mathrm{RH})$, and $\mathrm{f}_{\mathrm{ss}}(\mathrm{RH})$. As indicated in [30], $\mathrm{RH}$ values over than $95 \%$ are set equal to them at $\mathrm{RH}=95 \%$. For simplicity, the IMPROVE, Kiehl and Pitchford's method are referred to as M1, M2 and M3, respectively, later in this paper.

\section{Results}

\subsection{Performance of the NIER Operational Model (WRF-CMAQ)}

Before comparing the capability of AOD estimation between different methods, we summarized the performance of the NIER operational air quality system from the temporal distributions of daily $\mathrm{PM}_{2.5}$. Figure 3 shows a time series of observed and simulated daily $\mathrm{PM}_{2.5}$ concentrations in the Seoul (25 stations marked in Figure 1b) and Busan (19 stations) metropolitan areas from March 2016 to February 2017. The model was spun up for $12 \mathrm{~h}$ every day and daily $12 \mathrm{~h}$ (f12) and $35 \mathrm{~h}$ (f35) forecasts from 15:00 to 14:00 UTC the next day were compared with observations. The model results were interpolated to the location of the observation site using the Cressman method. Although the concentration of $\mathrm{PM}_{2.5}$ is higher in D01 compared with D02 in most periods, the operational forecast shows a reliable air pollutant simulation overall. Simulated values typically tend to be underestimated in summer and overestimated in winter; however, the model bias does not vary significantly over time. Therefore, we used all forecasts, except for the spin-up time, to investigate AOD estimation. A detailed analysis of the predictability of operational WRF-CMAQ using statistical scores is beyond the scope of this study; instead, we evaluated different algorithms of AOD estimation using the NIER operational model. 

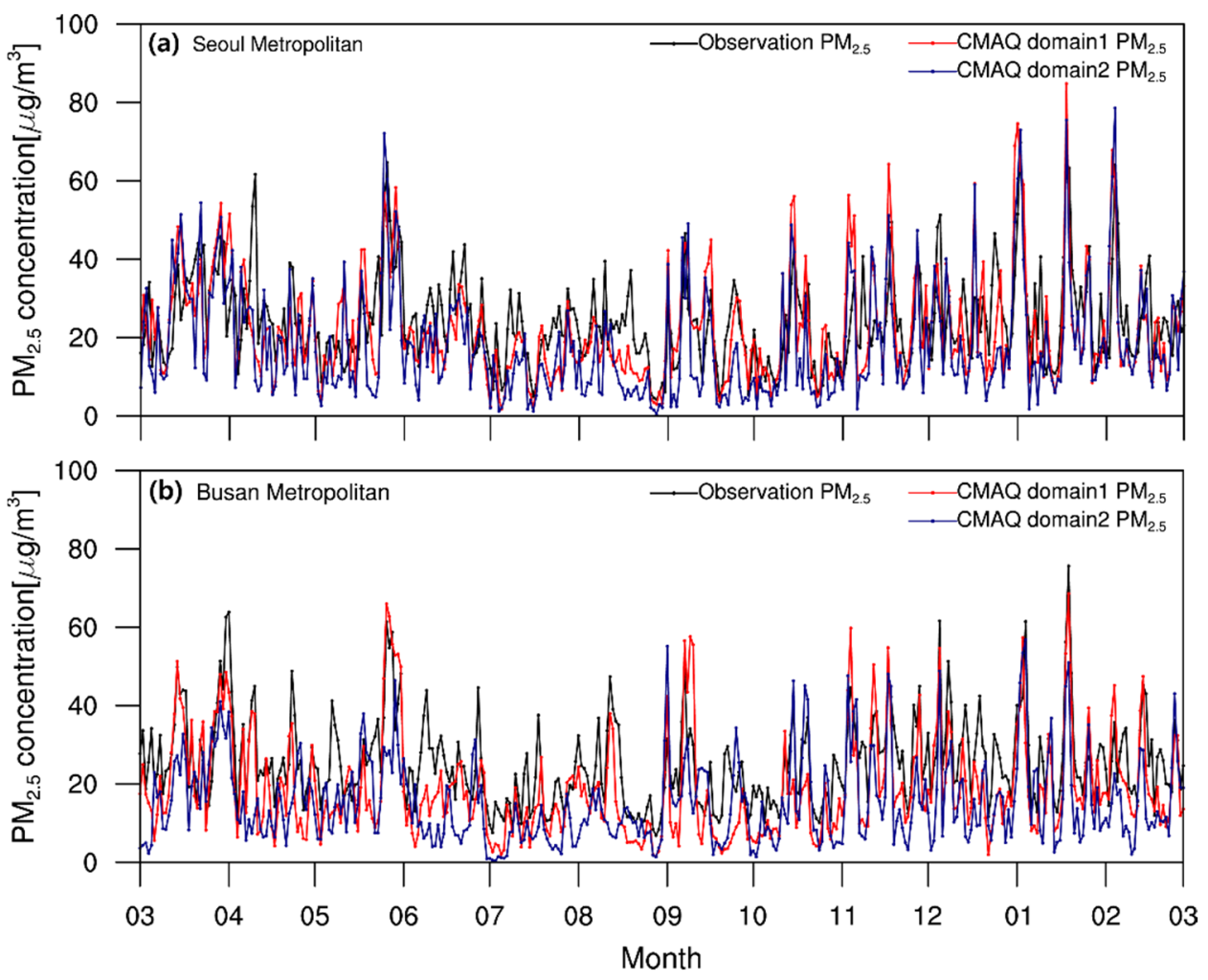

Figure 3. Time series of observed $\mathrm{PM}_{2.5}$ in (a) the Seoul and (b) the Busan metropolitan areas and forecasted daily $\mathrm{PM}_{2.5}$ from the $27 \mathrm{~km}$ resolution (red) and $9 \mathrm{~km}$ resolution (blue) operational forecasts of March 2016-February 2017.

\subsection{Validation of $A O D$ Estimation Methods}

Air pollution in South Korea is most severe in spring and winter [42-44]; therefore, we first focused on March-May 2016 (spring) and December 2016-February 2017 (winter). In general, finer grid spacing is expected to be relatively beneficial for simulating small-scale activities, such as regional circulation and local instability; thus, we investigated the performance of AOD estimation depending on grid resolution from the NIER operational model. Since the finest domain (D03) is too small to investigate AOD with satellite images, we only analyzed the model domains of D01 and D02 for East Asia and the Korean Peninsula, respectively. In this study, all statistical parameters are calculated using AERONET data, since satellite images (e.g., GOCI) cannot be used to evaluate the model outputs due to large cloud cover. However, each method's two-dimensional AOD is presented and compared with satellite image to reveal the key features of each estimation.

\subsubsection{Springtime}

Figure 4 displays the horizontal distribution of the observed and estimated AOD at 01:00 UTC on 31 May 2016, during the KORUS-AQ period. As shown in Figure 2, because the M1 method of Malm [11] with maximum RH values of $96 \%$ and $98 \%$ tends to overestimate AOD, we only present the results with a maximum $\mathrm{RH}$ value of $93 \%$. In Figure $4 a$, the GOCI satellite image shows large missing areas in most cloud regions where synoptic lows have collapsed; however, there is high-AOD from eastern China to the mid-western coastal region of the Korean Peninsula, crossing the Yellow Sea. Although the estimated algorithms for AOD use the same model results, their diagnosed AOD patterns are very different, especially in the cloud region, regardless of the grid resolution. In the D01 analysis, M1 (Figure $4 \mathrm{~b}$ ) shows high AOD along the missing regions from a satellite image; in contrast, reduced values of AOD were output by the M2 and M3 methods (Figure 4c,d, respectively). Since most values from clouds are missing in satellite observations, no 
quantitative validation can be performed (Figure $4 \mathrm{~b}-\mathrm{d}$ ). Thus, other validations using ground observations are discussed later using detailed statistics.
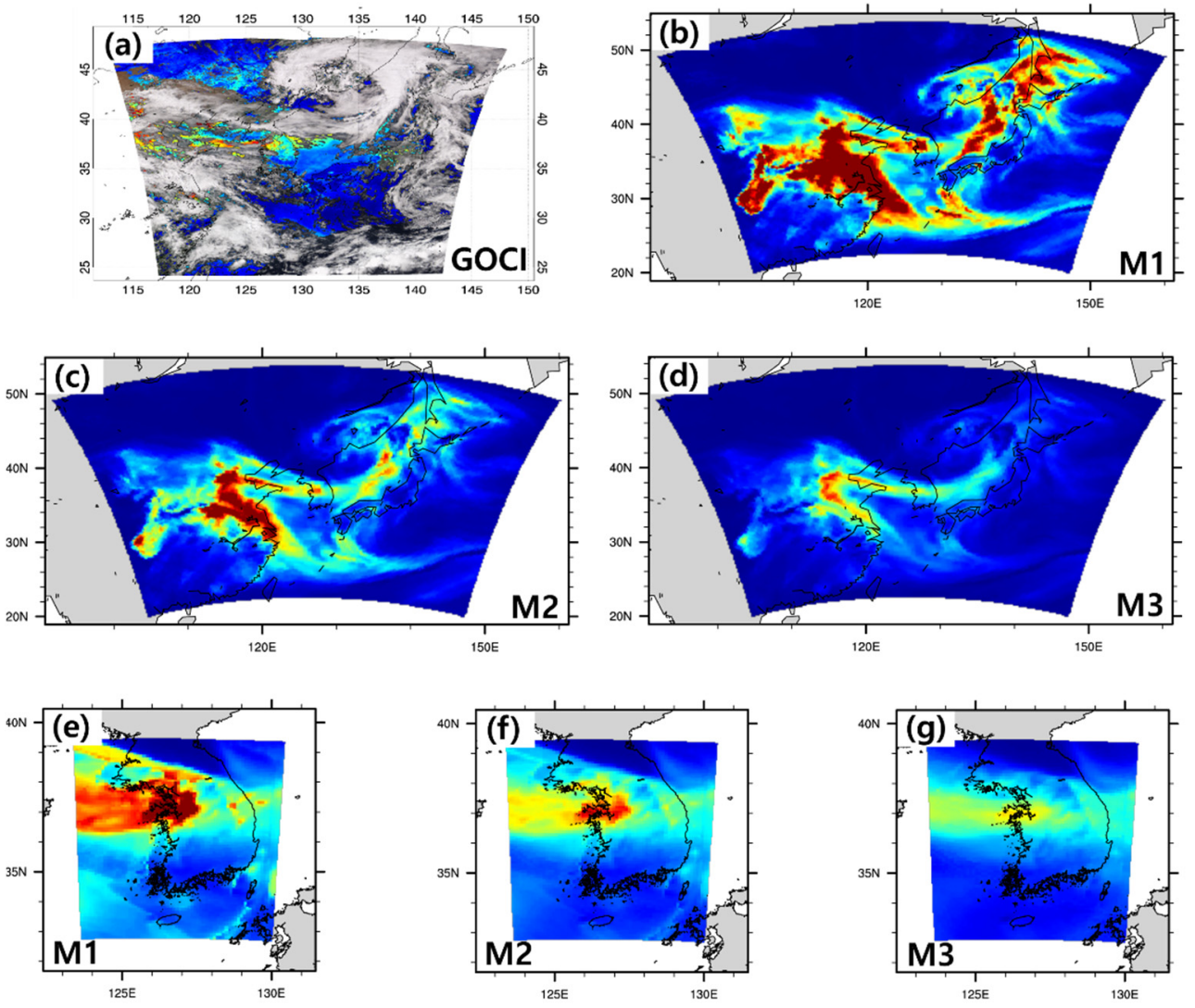

$0 \quad 0.10 .20 .30 .40 .50 .60 .70 .80 .9111 .11 .21 .31 .41 .511 .61 .71 .81 .92$

Figure 4. (a) Spatial distribution of aerosol optical depth (AOD) obtained from the geostationary ocean color imager (GOCI) satellite at 01:00 UTC on 31 May 2016. Estimated AOD from $27 \mathrm{~km}$ resolution model results using (b) M1 with maximum relative humidity $(\mathrm{RH})=93 \%$, (c) $\mathrm{M} 2$, and (d) M3. (e-g) Estimated AODs from the $9 \mathrm{~km}$ resolution model using the (e) M1, (f) M2, and (g) M3 method.

From a $9 \mathrm{~km}$ resolution model around the Korean Peninsula (Figure 4e,f), more detailed distributions were simulated and compared with the coarse grid results. High AOD values are apparent in the Seoul metropolitan area, and a strong AOD gradient is evident in the northern area of the western inflow (Figure 4e). However, as shown in Figure 4f,g, the AOD is reduced in the central Korean Peninsula, and the northern edge of the strong gradient is also weaker than that of the M1 method.

Statistical robustness was determined using long-term analysis of the time series and quantitative comparisons were carried out using ground observations (Figure 5). Figure 5 shows observed and estimated AOD values during March-May 2016. There are 11 AERONET stations in the Seoul metropolitan area; we selected the Yonsei-YSU AERONET station (marked as a large red dot in Figure 1b) because it has the fewest missing value during our analysis period. However, we also performed a comparative statistical analysis using multiple stations for the entire numerical domain (see Section 3.2.3). To the best of our knowledge, the model's ability to estimate AOD is usually investigated in large domains, and past studies have tested the method on a regional scale. The estimated AOD values from the WRF-CMAQ model were interpolated to the location of the observation station using Cressman interpolation. Both the observation and model results were averaged daily; Figure 5a,b represent the results from D01 and D02, respectively. From the $27 \mathrm{~km}$ grid 
(Figure 5a), all estimated AODs show similar temporal variation to the observed AOD, but their difference is significant when high peaks of AOD are simulated. The estimated AOD using the M1 method with a maximum $\mathrm{RH}$ of $96 \%$ was almost twice that for a maximum $\mathrm{RH}$ of $93 \%$, offering evidence of uncertainty in this method. The finer-grid AOD also suffered from these overestimations (Figure $5 b$ ), but the M2 and M3 methods were more accurate than the M1 method in both D01 and D02, with the M3 estimation showing the smallest AOD among the algorithms. These results are consistent with those shown in Figure 4. It is noteworthy that there are some underestimations within the M3 results, particularly for high-AOD cases.
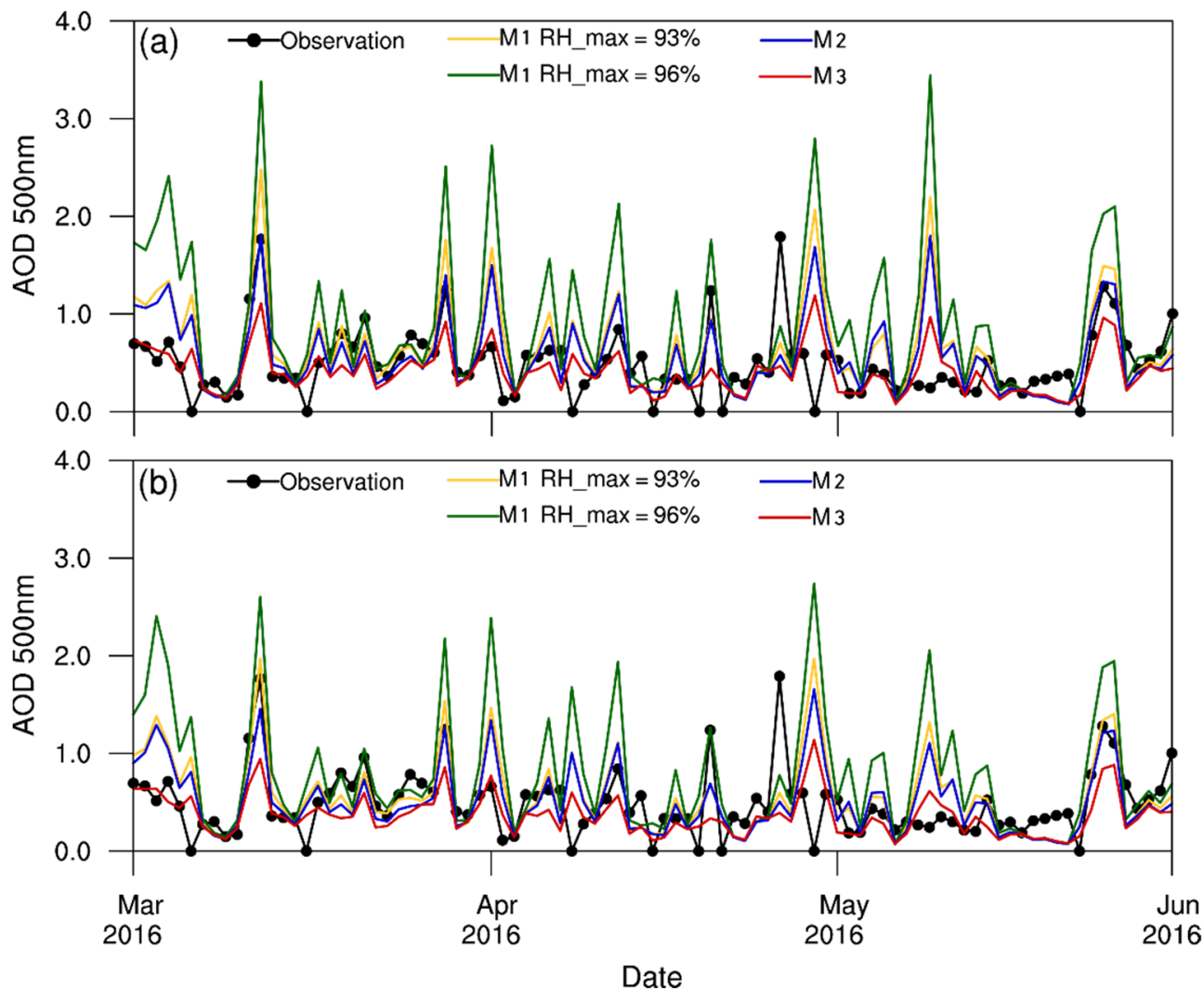

Figure 5. Time series of daily aerosol optical depth (AOD) from the Yonsei-YSU Aerosol Robotic Network (AERONET) station (black) and estimated AOD from the forecast model during MarchMay 2016 (springtime). Estimated AODs in (a,b) represent the 27 and $9 \mathrm{~km}$ resolution model results, respectively. Yellow, green, blue, and red lines indicate M1 with maxRH $=93 \%$, M1 with $\operatorname{maxRH}=96 \%), M 2$, and M3, respectively.

Statistical analysis for the Seoul metropolitan area during springtime is shown in Figure 6 using the data from Figure 5. Statistical scores with correlation (R), root mean square error (RMSE), and mean bias (MB) are displayed in each plot. The R-values are all between 0.24 and 0.3 , which is significantly lower than those reported in previous studies (e.g., [45,46]) from WRF-CMAQ around the Korean Peninsula. The lower performance of the model can be attributed to two possible factors: (1) the small number of observations and (2) local features of observational points that are not included in the model. Because of error terms or extreme values from observation, local statistics can show bad performance. As indicated in Koo [47], the impact of hygroscopic growth factors on AOD can differ among observational locations. Further studies are required to address this issue. At $27 \mathrm{~km}$ resolution, the M1 method exhibited positive biases, with a value of $0.16(0.42)$ for a maximum $\mathrm{RH}$ of $93 \%(96 \%)$. However, the MB of the M2 was half that of the M1 method, while the M3 only showed a negative bias of -0.08 , which is consistent with its 
underestimation tendency. Visual differences between the coarse and fine resolutions are not significant, but the absolute value of MB decreased in the $9 \mathrm{~km}$ grid for both the M1 and M2 methods. The M3 estimation was not sensitive to the model grid size in terms of MB. The other statistical values saw no significant improvement when using the higher resolution model with any of the methods.
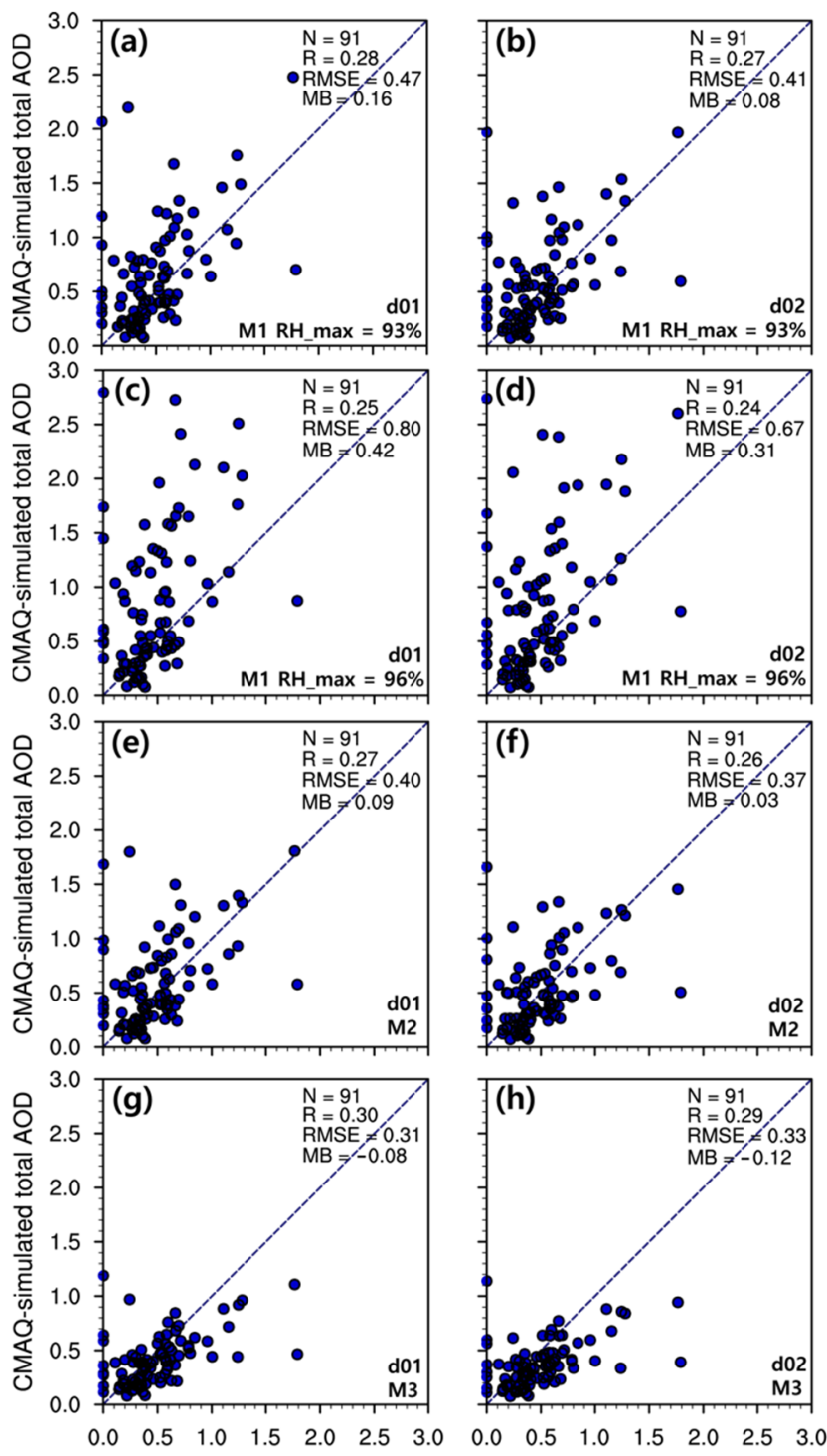

AERONET-Observation total AOD AERONET-Observation total AOD

Figure 6. Daily aerosol optical depth (AOD) from the Yonsei-YSU station and estimated AOD from the forecast model during March-May 2016. The left and right panels represent the results from the 27 and $9 \mathrm{~km}$ resolution model results, respectively. Estimation methods are (a,b) M1 with max $\mathrm{RH}=93 \%$, (c,d) M1 with $\mathrm{RH}=96 \%,(\mathbf{e}, \mathbf{f}) \mathrm{M} 2$, and (g,h) M3.

\subsubsection{Wintertime}

We further examined the seasonal sensitivity of each method through an additional case analysis for winter. Figure 7 displays the horizontal distribution of observed and estimated AOD at 01:00 UTC on 2 January 2017 over East Asia and the Korean Peninsula. While the GOCI satellite missed the AOD for most of the East Asia region (Figure 7a), the estimated AODs of all methods showed large values in the missing region (southern China and the central Korean Peninsula; Figure $7 \mathrm{~b}-\mathrm{d}$ ). Unlike springtime, the M2 method showed an AOD similar to that of the M1 method. However, the M3 method still showed the lowest AOD. For the $9 \mathrm{~km}$ resolution analysis (Figure $7 \mathrm{~g}$ ), reduced AOD estimation by the M3 
method was significant on the eastern and the southern Korean Peninsula and for the Seoul Metropolitan area compared with the other methods Figure 7e,f). Although the observable area from the satellite image in Figure 7a is very small, the M3 estimation might be the closest to the satellite comparing the eastern side of the Korean Peninsula.
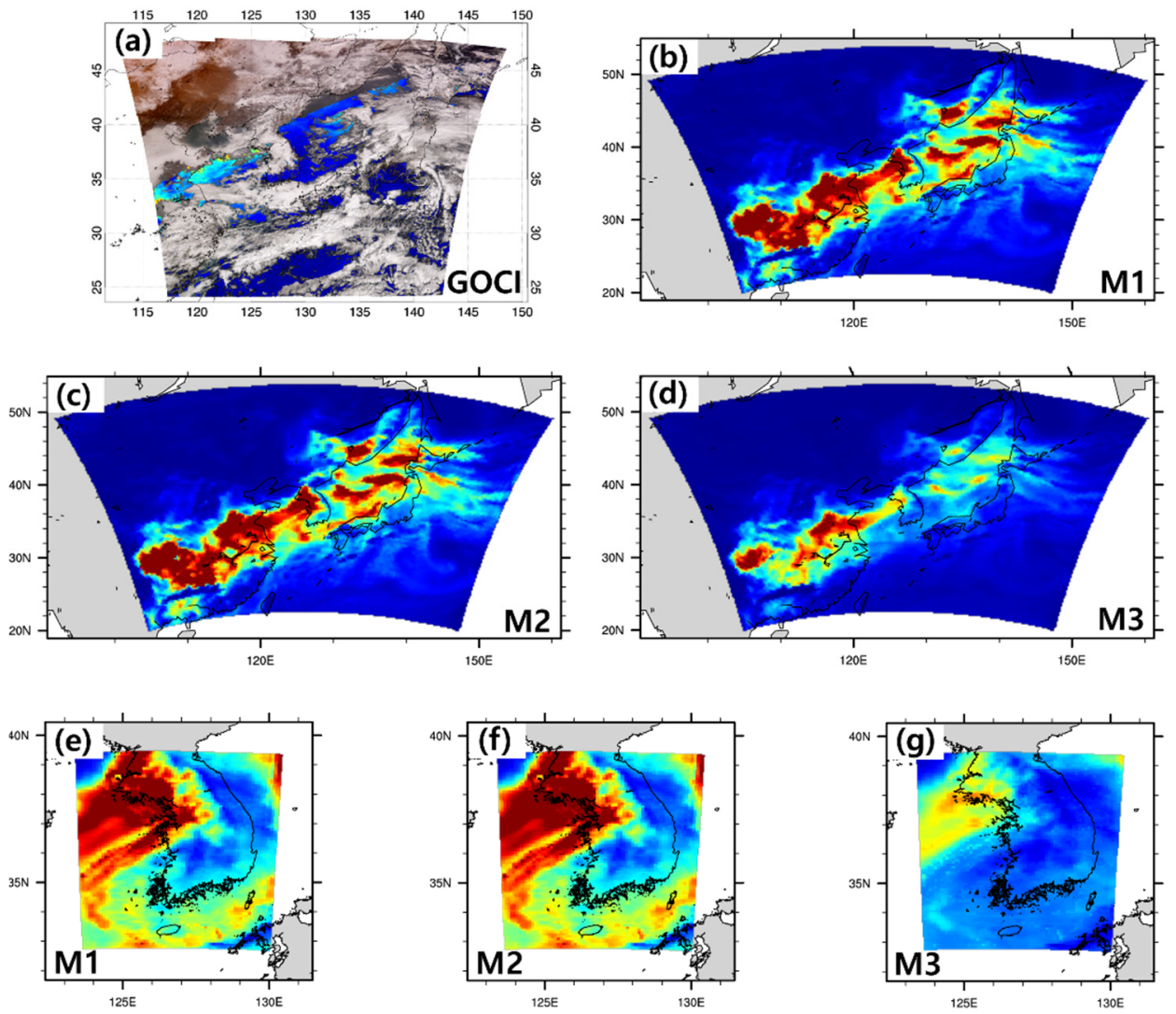

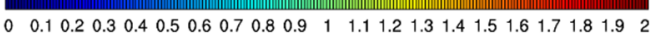

Figure 7. (a) Spatial distribution of aerosol optical depth (AOD) obtained from the geostationary ocean color imager (GOCI) satellite at 01:00 UTC on 2 January 2017. Estimated AOD from $27 \mathrm{~km}$ resolution model results using (b) M1 with maximum relative humidity (RH) $=93 \%$, (c) M2, and (d) M3. (e-g) Estimated AODs from the $9 \mathrm{~km}$ resolution model using (e) M1, (f) M2, and (g) M3.

The daily variation in AODs was compared at the Yonsei University AERONET station (Figures 8 and 9). All estimated AODs were closer to the AERONET observation in wintertime than in springtime, and the overestimation tendency was not very significant in winter. Interestingly, high-concentration PM2.5 $\left(\mathrm{PM}_{2.5}>35 \mu \mathrm{g} \mathrm{m}^{-3}\right)$ events were more frequent in winter (32 days) than in springtime (17 days) during our analysis period, but wintertime estimations showed good agreement with the overall observations. Although differences between estimation methods still exist, especially in the high-concentration AOD period (Figure 8a), these are reduced with high resolution (Figure 8b). Furthermore, there is no underestimation by the M3 algorithm, in contrast to the springtime for both the D01 and D02. Most statistical scores were similar or better than those in springtime (e.g., enhanced R and RMSE); however, for the M2 method, RMSE and MB increased and were similar to those of the M1 method with maximum $\mathrm{RH}=93 \%$ (Figure 9). 


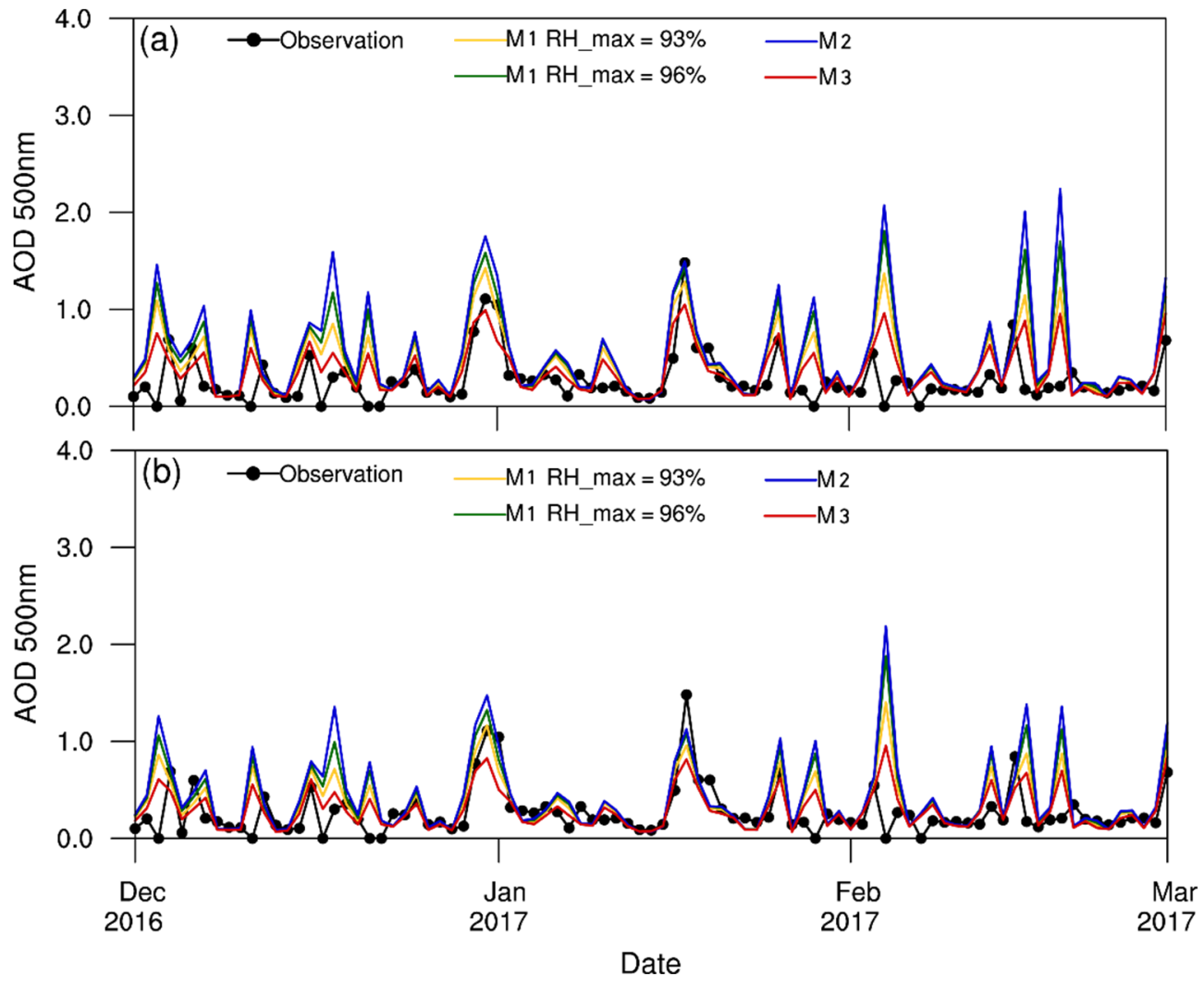

Figure 8. Time series of daily aerosol optical depth (AOD) from the Yonsei-YSU Aerosol Robotic Network (AERONET) station (black) and estimated AOD from the forecast model during December 2016-March 2017 (wintertime). Estimated AODs in (a,b) represent the 27 and $9 \mathrm{~km}$ resolution model results, respectively. Yellow, green, blue, and red lines indicate M1 with maxRH $=93 \%$, M1 with $\operatorname{maxRH}=96 \%$, M2, and M3, respectively.

\subsubsection{Statistical Analysis for the Entire Numerical Domain}

Previously, we verified AOD estimations using a single ground observation, focusing on the Seoul metropolitan area. To expand our analysis for the entire domain of the NIER operational model, we also evaluated AOD estimation for wider regions over both East Asia and the Korean Peninsula. The AOD from the $27 \mathrm{~km}$ grid was compared with the 15 sites of the AERONET station in East Asia, and the $9 \mathrm{~km}$ grid was compared with the six sites on the Korean Peninsula, as shown in Figure 1a. We selected these observational stations because other stationary data had missing values of longer than 30 days during our analysis period.

Statistical analyses of AERONET and estimated AODs are summarized in Table 3 for all periods in terms of R, RMSE, and MB. The number of observed data points used in these analyses are also shown; there is seasonal variation in these numbers. Regardless of the estimation method, all AODs gave small values of MB, confirming good performance; this is in contrast to the single observational comparison shown in Figure 9, despite being from a $9 \mathrm{~km}$ grid. For D01, all the $\mathrm{R}$ values were larger than those from a single observational value. The $R$ values were highest during summer and lowest during springtime for all estimations. For the M3 estimation, all R values were better than those of M1 and M2's estimation. This raises the same question as that raised in Section 3.2.1 from the single observational analysis, but understanding the discrepancy between large and local regions would be challenging. Analyzing RMSE with R, the M1 method with maximum RH $=93 \%$ was superior to the M2 during all seasons, even though the M2 method gave a good performance for the Seoul metropolitan area. The best skill score was still obtained using the M3 estimation, consistent with the single observational comparison. The highest $\mathrm{R}$ 
and lowest RMSE were obtained by the M3 method for both D01 and D02. From the D02 analysis, the statistical results were similar to those of D01, except for the R values.
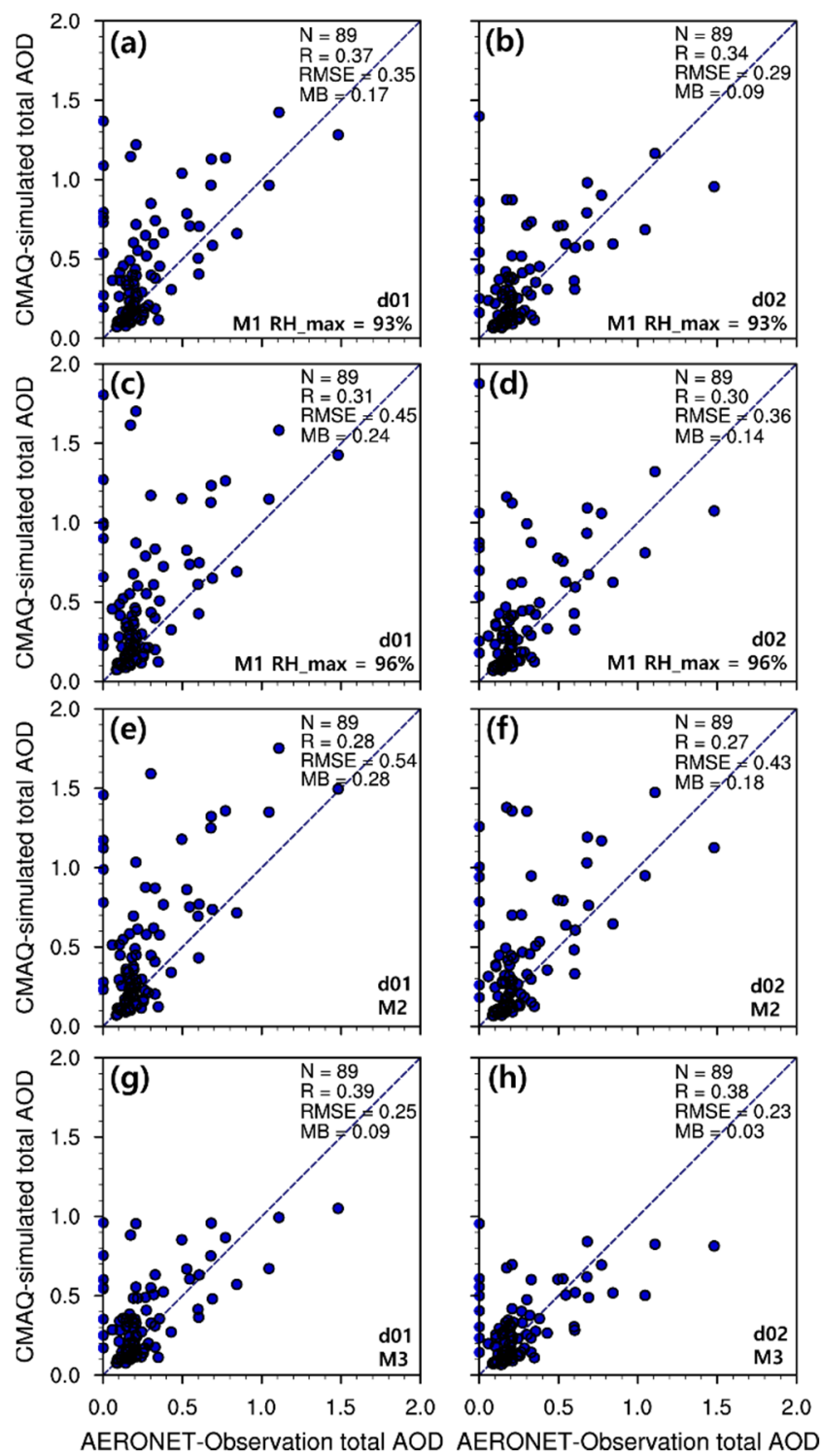

Figure 9. Daily aerosol optical depth (AOD) from the Yonsei-YSU station and estimated AOD from the forecast model during December 2016-March 2017 (wintertime). The left and right panels represent the results from the 27 and $9 \mathrm{~km}$ resolution model results, respectively. Estimation methods are (a,b) M1 with $\max \mathrm{RH}=93 \%$, (c,d) M1 with $\max \mathrm{RH}=96 \%,(\mathbf{e}, \mathbf{f}) \mathrm{M} 2$, and (g,h) M3. 
Table 3. Statistical values between daily aerosol optical depth (AOD) from 15 Aerosol Robotic Network (AERONET) stations and estimated AOD from the forecast models during March 2016-February 2017.

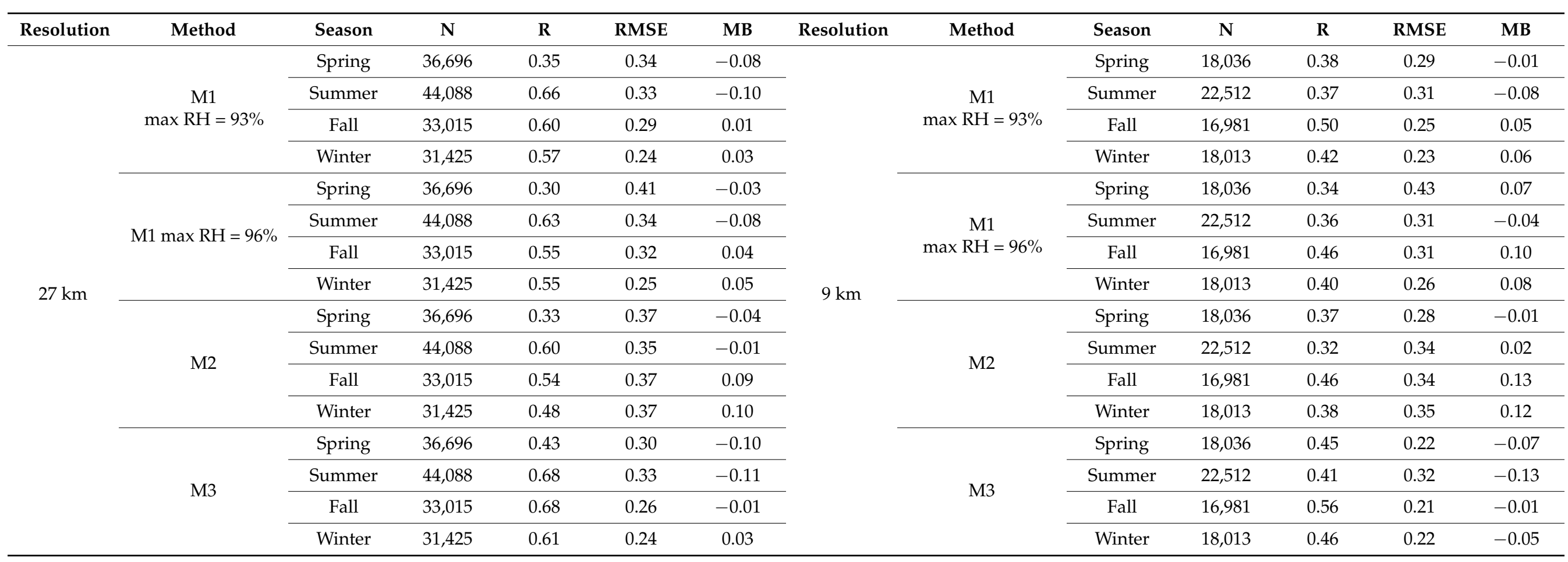




\section{Summary and Conclusions}

AOD retrieval from satellites can provide reliable information, but missing values are problematic when cloud fractions are continually high. Instead of real observations, a numerical model can be used to make up for missing data. In this study, to investigate the consistency of AOD estimations, the AOD calculation ability of the NIER operational numerical forecast model (WRF-CMAQ) was verified through comparative analysis. The greatest uncertainty in the M1 (IMPROVE) method [15] is related to $f(R H)$, which corresponds to the cloud and aerosol hygroscopic growth factor. The AODs are very sensitive to the set value of the maximum relative humidity, especially around cloudy regions where relative humidity is close to 1 . To remove this uncertainty, we tested two alternative estimations $[29,30]$ in which it is not necessary to set the maximum value of relative humidity.

When comparing GOCI-retrieved and WRF-CMAQ-derived AODs for spring and winter, the M1 estimation with maximum $\mathrm{RH}=96 \%$ showed the largest values, while those of the M3 method were the smallest. These results are consistent with a single observational analysis for the Seoul Metropolitan. However, the statistics should be treated with caution, since all $\mathrm{R}$ values were significantly lower than those in a previous study; identifying the reasons for this requires further study considering local features of AOD with large observational points. Other statistics, such as RMSE and MB, are dependent on model resolution and the analyzed period. AOD estimations are not always improved at high resolution, and their seasonal dependency is apparent. Underestimations and overestimations were reduced during winter compared with springtime for the M3 and other estimation methods, respectively.

To extend our analysis to a larger domain, we also carried out a statistical investigation for NIER D01 and D02. All AODs performed well, showing small MB values. The values of $\mathrm{R}$ in D01 were larger than the single observational values and were comparable to those reported in the literature. However, from the D02 analysis, R was significantly lower than that of D01. For the M3 estimation, values were $>0.5$, but for all other methods, the values were $<0.5$. A small number of observations and/or local characteristics of AOD can cause these results and it will be a challenge to investigate this issue in future studies. In general, the $\mathrm{R}$ values were highest during summer and lowest during springtime for all methods. Overall, the M3 gave the best scores in the large domain analysis. To the best of our knowledge, M1 is still widely used to derive AOD from WRF-CMAQ. While our results only represent a 1-year data analysis, care should be taken when performing AOD estimation, and empirically reconstructed mass-extinction methods, such as that of M3, offer an alternative solution.

Author Contributions: Conceptualization S.-H.P., H.-J.K., W.J.C. and C.H.J.; methodology, S.-H.P., H.-J.K. and U.S.; software, H.-J.K.; validation, H.-J.K. and U.S.; formal analysis, H.-J.K., J.-H.K., C.H.J., W.J.C. and K.-P.N.; investigation, H.-J.K. and J.-H.K.; resources, W.J.C. and K.-P.N.; writing-original draft preparation, S.-H.P., H.-J.K. and U.S. All authors have read and agreed to the published version of the manuscript.

Funding: This research was supported by a grant from the National Institute of Environment Research (NIER), funded by the Ministry of Environment (MOE) of the Republic of Korea (e.x. NIER-201901-02-085). (S-H.P.) This work was also supported by the National Research Foundation of Korea (NRF) grant funded by the Korea government (MEST; 2021R1A2C1012433) and (in part) by the Yonsei University Future-leading Research Initiative of 2018-22-0021.

Institutional Review Board Statement: Not applicable.

Informed Consent Statement: Not applicable.

Acknowledgments: We would like to acknowledge the use of the GOCI product (Joon, K.; M.J. Choi). We also thank NIER's operational team for developing and maintaining the air-quality forecasting system.

Conflicts of Interest: The authors declare no conflict of interest. 


\section{Appendix A}

Table A1. Water growth in the small- and large-sized sulfate and nitrate components.

\begin{tabular}{|c|c|c|c|c|c|c|c|c|}
\hline RH(\%) & $f_{S}(R H)$ & $\mathrm{f}_{\mathrm{L}}(\mathrm{RH})$ & RH(\%) & $f_{S}(R H)$ & $f_{L}(R H)$ & RH(\%) & $f_{S}(R H)$ & $f_{L}(R H)$ \\
\hline $0 \sim 36$ & 1.00 & 1.00 & 56 & 1.78 & 1.61 & 76 & 2.60 & 2.18 \\
\hline 37 & 1.38 & 1.31 & 57 & 1.81 & 1.63 & 77 & 2.67 & 2.22 \\
\hline 38 & 1.40 & 1.32 & 58 & 1.83 & 1.65 & 78 & 2.75 & 2.27 \\
\hline 39 & 1.42 & 1.34 & 59 & 1.86 & 1.67 & 79 & 2.84 & 2.33 \\
\hline 40 & 1.44 & 1.35 & 60 & 1.89 & 1.69 & 80 & 2.93 & 2.39 \\
\hline 41 & 1.46 & 1.36 & 61 & 1.92 & 1.71 & 81 & 3.03 & 2.45 \\
\hline 42 & 1.48 & 1.38 & 62 & 1.95 & 1.73 & 82 & 3.16 & 2.52 \\
\hline 43 & 1.49 & 1.39 & 63 & 1.99 & 1.75 & 83 & 3.27 & 2.60 \\
\hline 44 & 1.51 & 1.41 & 64 & 2.02 & 1.78 & 84 & 3.42 & 2.69 \\
\hline 45 & 1.53 & 1.42 & 65 & 2.06 & 1.80 & 85 & 3.58 & 2.79 \\
\hline 46 & 1.55 & 1.44 & 66 & 2.09 & 1.83 & 86 & 3.76 & 2.90 \\
\hline 47 & 1.57 & 1.45 & 67 & 2.13 & 1.86 & 87 & 3.98 & 3.02 \\
\hline 48 & 1.59 & 1.47 & 68 & 2.17 & 1.89 & 88 & 4.23 & 3.16 \\
\hline 49 & 1.62 & 1.49 & 69 & 2.22 & 1.92 & 89 & 4.53 & 3.33 \\
\hline 50 & 1.64 & 1.50 & 70 & 2.26 & 1.95 & 90 & 4.90 & 3.53 \\
\hline 51 & 1.66 & 1.52 & 71 & 2.31 & 1.98 & 91 & 5.35 & 3.77 \\
\hline 52 & 1.68 & 1.54 & 72 & 2.36 & 2.01 & 92 & 5.93 & 4.06 \\
\hline 53 & 1.71 & 1.55 & 73 & 2.41 & 2.05 & 93 & 6.71 & 4.43 \\
\hline 54 & 1.73 & 1.57 & 74 & 2.47 & 2.09 & 94 & 7.78 & 4.92 \\
\hline 55 & 1.76 & 1.59 & 75 & 2.54 & 2.13 & 95 & 9.34 & 5.57 \\
\hline
\end{tabular}

Table A2. Sea salt particle diameter growth and water growth function.

\begin{tabular}{|c|c|c|c|c|c|}
\hline RH(\%) & $\begin{array}{l}\text { Growth } \\
\text { Factor }\end{array}$ & $\mathrm{f}_{\mathrm{SS}}(\mathrm{RH})$ & RH(\%) & $\begin{array}{l}\text { Growth } \\
\text { Factor }\end{array}$ & $\mathrm{f}_{\mathrm{SS}}(\mathrm{RH})$ \\
\hline $1 \sim 46$ & 1.0000 & 1.0000 & 71 & 1.8434 & 3.1269 \\
\hline 47 & 1.5922 & 2.3584 & 72 & 1.8589 & 3.1729 \\
\hline 48 & 1.6001 & 2.3799 & 73 & 1.8751 & 3.2055 \\
\hline 49 & 1.6081 & 2.4204 & 74 & 1.8921 & 3.2459 \\
\hline 50 & 1.6162 & 2.4488 & 75 & 1.9100 & 3.2673 \\
\hline 51 & 1.6245 & 2.4848 & 76 & 1.9288 & 3.3478 \\
\hline 52 & 1.6329 & 2.5006 & 77 & 1.9488 & 3.4174 \\
\hline 53 & 1.6415 & 2.5052 & 78 & 1.9700 & 3.5202 \\
\hline 54 & 1.6503 & 2.5279 & 79 & 1.9925 & 3.5744 \\
\hline 55 & 1.6593 & 2.5614 & 80 & 2.0166 & 3.6329 \\
\hline 56 & 1.6685 & 2.5848 & 81 & 2.0423 & 3.6905 \\
\hline 57 & 1.6779 & 2.5888 & 82 & 2.0701 & 3.8080 \\
\hline 58 & 1.6875 & 2.6160 & 83 & 2.1001 & 3.9505 \\
\hline 59 & 1.6974 & 2.6581 & 84 & 2.1328 & 4.0398 \\
\hline 60 & 1.7075 & 2.6866 & 85 & 2.1684 & 4.1127 \\
\hline 61 & 1.7179 & 2.7341 & 86 & 2.2077 & 4.2824 \\
\hline 62 & 1.7286 & 2.7834 & 87 & 2.2512 & 4.4940 \\
\hline 63 & 1.7397 & 2.8272 & 88 & 2.2999 & 4.6078 \\
\hline 64 & 1.7511 & 2.8287 & 89 & 2.3548 & 4.8573 \\
\hline 65 & 1.7629 & 2.8594 & 90 & 2.4174 & 5.1165 \\
\hline 66 & 1.7751 & 2.8943 & 91 & 2.4898 & 5.3844 \\
\hline 67 & 1.7877 & 2.9105 & 92 & 2.5749 & 5.7457 \\
\hline 68 & 1.8008 & 2.9451 & 93 & 2.6769 & 6.1704 \\
\hline 69 & 1.8145 & 3.0105 & 94 & 2.8021 & 6.7178 \\
\hline 70 & 1.8286 & 3.0485 & 95 & 2.9610 & 7.3492 \\
\hline
\end{tabular}




\section{References}

1. Haywood, J.; Boucher, O. Estimates of the direct and indirect radiative forcing due to tropospheric aerosols: A review. Rev. Geophys. 2000, 38, 513-543. [CrossRef]

2. Xun, L.; Lu, H.; Qian, C.; Zhang, Y.; Lyu, S.; Li, X. Analysis of aerosol optical depth from sun photometer at Shouxian, China. Atmosphere 2021, 12, 1226. [CrossRef]

3. Jung, C.H.; Yoon, Y.J.; Um, J.; Lee, S.S.; Han, K.M.; Shin, H.J.; Lee, J.Y.; Kim, Y.P. Approximated expression of the hygroscopic growth factor for polydispersed aerosols. J. Aerosol. Sci. 2021, 151, 105670. [CrossRef]

4. Li, J.; Han, Z.; Zhang, R. Influence of aerosol hygroscopic growth parameterization on aerosol optical depth and direct radiative forcing over East Asia. Atmos. Res. 2014, 140, 14-27. [CrossRef]

5. Kim, D.-R.; Choi, W.-J.; Choi, M.; Kim, J.; Cho, A.; Kim, S.-K.; Kim, J.; Moon, K. Analysis of aerosol optical properties for high particulate matters and light Asian dust in Seoul Using GOCI. J. Korean Soc. Atmos. Environ. 2017, 33, 233-240. [CrossRef]

6. Choi, M.; Kim, J.; Lee, J.; Kim, M.; Park, Y.J.; Holben, B.; Eck, T.F.; Li, Z.; Song, C.H. GOCI Yonsei aerosol retrieval version 2 products: An improved algorithm and error analysis with uncertainty estimation from 5-year validation over East Asia. Atmos. Meas. Tech. 2018, 11, 385-408. [CrossRef]

7. Kim, J.; Kim, M.; Choi, M. Air Pollution in Eastern Asia: An Integrated Perspective. Air Pollut. East. Asia Integr. Perspect. 2017, 323-333. [CrossRef]

8. Zhao, Y.; Nielsen, C.P.; Lei, Y.; McElroy, M.B.; Hao, J. Quantifying the uncertainties of a bottom-up emission inventory of anthropogenic atmospheric pollutants in China. Atmos. Chem. Phys. 2011, 11, 2295-2308. [CrossRef]

9. Gilliam, R.C.; Hogrefe, C.; Godowitch, J.M.; Napelenok, S.; Mathur, R.; Rao, S.T. Impact of inherent meteorology uncertainty on air quality model predictions. J. Geophys. Res. Atmos. 2015, 120, 12259-12280. [CrossRef]

10. Holnicki, P.; Nahorski, Z. Emission data uncertainty in urban air quality modeling-Case study. Environ. Model. Assess. 2015, 20, 583-597. [CrossRef]

11. Huang, J.; McQueen, J.; Wilczak, J.; Djalalova, I.; Stajner, I.; Shafran, P.; Allured, D.; Lee, P.; Pan, L.; Tong, D.; et al. Improving NOAA NAQFC PM2.5 predictions with a bias correction approach. Weather Forecast. 2017, 32, 407-421. [CrossRef]

12. Tang, Y.; Pagowski, M.; Chai, T.; Pan, L.; Lee, P.; Baker, B.; Kumar, R.; Delle Monache, L.; Tong, D.; Kim, H.-C. 3D-Var versus Optimal Interpolation for Aerosol Assimilation: A Case Study over the Contiguous United States. Geosci. Model Dev. Discuss. 2017, 10, 1-27. [CrossRef]

13. Choi, Y.; Chen, S.H.; Huang, C.C.; Earl, K.; Chen, C.Y.; Schwartz, C.S.; Matsui, T. Evaluating the impact of assimilating aerosol optical depth observations on dust forecasts over North Africa and the East Atlantic using different data assimilation methods. J. Adv. Model. Earth Syst. 2020, 12, 1-30. [CrossRef] [PubMed]

14. Cheng, F.Y.; Feng, C.Y.; Yang, Z.M.; Hsu, C.H.; Chan, K.W.; Lee, C.Y.; Chang, S.C. Evaluation of real-time PM2.5 forecasts with the WRF-CMAQ modeling system and weather-pattern-dependent bias-adjusted PM2.5 forecasts in Taiwan. Atmos. Environ. 2021, 244, 117909. [CrossRef]

15. Malm, C.; Sisler, J.F.; Cahill, A. Spatial and seasonal trends in particle concetration and optical extinction in the United States. J. Geophys. Res. Atmos. 1994, 99, 1347-1370. [CrossRef]

16. Pitchford, M.; Malm, W.; Schichtel, B.; Kumar, N.; Lowenthal, D.; Hand, J. Revised algorithm for estimating light extinction from IMPROVE particle speciation data. J. Air Waste Manag. Assoc. 2007, 57, 1326-1336. [CrossRef]

17. Eichler, H.; Cheng, Y.F.; Birmili, W.; Nowak, A.; Wiedensohler, A.; Brüggemann, E.; Gnauk, T.; Herrmann, H.; Althausen, D.; Ansmann, A.; et al. Hygroscopic properties and extinction of aerosol particles at ambient relative humidity in South-Eastern China. Atmos. Environ. 2008, 42, 6321-6334. [CrossRef]

18. Chen, J.; Zhao, C.S.; Ma, N.; Yan, P. Aerosol hygroscopicity parameter derived from the light scattering enhancement factor measurements in the North China Plain. Atmos. Chem. Phys. 2014, 14, 8105-8118. [CrossRef]

19. Wang, X.; Shen, X.J.; Sun, J.Y.; Zhang, X.Y.; Wang, Y.Q.; Zhang, Y.M.; Wang, P.; Xia, C.; Qi, X.F.; Zhong, J.T. Size-resolved hygroscopic behavior of atmospheric aerosols during heavy aerosol pollution episodes in Beijing in December 2016. Atmos. Environ. 2018, 194, 188-197. [CrossRef]

20. Zhang, Y.; Wang, Y.; Zhang, X.; Shen, X.; Sun, J.; Wu, L.; Zhang, Z.; Che, H. Chemical components, variation, and source identification of PM1 during the heavy air pollution episodes in Beijing in December 2016. J. Meteorol. Res. 2018, $32,1-13$. [CrossRef]

21. Byun, D.W.; Ching, J.K.S. Science Algorithms of the EPA Models-3 Community Multiscale Air Quality (CMAQ) modeling system. United States Environ. Prot. Agency 1999, 44, 1765-1778.

22. Byun, D.; Schere, K.L. Review of the governing equations, computational algorithms, and other components of the models-3 Community Multiscale Air Quality (CMAQ) modeling system. Appl. Mech. Rev. 2006, 59, 51-76. [CrossRef]

23. Skamarock, W.C.; Klemp, J.B.; Dudhia, J.B.; Gill, D.O.; Barker, D.M.; Duda, M.G.; Huang, X.-Y.; Wang, W.; Powers, J.G. A Description of the Advanced Research WRF Version 3, NCAR Technical Note TN-475+STR; Technical Report; NCAR: Boulder, CO, USA, 2008. Available online: https:/ / opensky.ucar.edu/islandora/object/technotes:500 (accessed on 18 January 2022).

24. Myoung, J.; Kim, T.; Lee, Y.; Suh, I.; Jang, L. Optimization of the computing environment to improve the speed of the modeling (WRF and CMAQ) calculation of the National Air Quality Forecast System. J. Environ. Sci. Int. 2018, 27, 723-735. [CrossRef] 
25. Choi, K.-C.; Lim, Y.; Lee, J.-B.; Nam, K.; Lee, H.; Lee, Y.; Myoung, J.; Kim, T.; Jang, L.; Kim, J.S.; et al. Evaluation of the simulated PM2.5 concentrations using air quality forecasting system according to emission inventories-Focused on China and South Korea. J. Korean Soc. Atmos. Environ. 2018, 34, 306-320. [CrossRef]

26. Carter, W.P.L. Documentation of the Saprc-99 chemical mechanism for VOC reactivity assessment- draft for review purposes only not for attribution. Contract 1999, 92, 95-308.

27. Woo, J.-H. MIX: A mosaic Asian anthropogenic emission inventory for the MICS-Asia and the HTAP projects. Atmos. Chem. Phys. Discuss. 2015, 15, 34813-34869. [CrossRef]

28. Benjey, W.; Houyoux, M.; Susick, J. Implementation of the SMOKE emission data processor and SMOKE tool input data processor in models-3. In Proceedings of the Emission Inventory Conference, Denver, CO, USA, 1-4 May 2001.

29. Guenther, A.; Karl, T.; Harley, P.; Weidinmyer, C.; Palmer, P.I.; Geron, C. Edinburgh Research Explorer Estimates of global terrestrial isoprene emissions using MEGAN (Model of Emission of Gases and Aerosols from Nature). Atmos. Chem. Phys. 2006, 3181-3210. [CrossRef]

30. Guenther, A.B.; Jiang, X.; Heald, C.L.; Sakulyanontvittaya, T.; Duhl, T.; Emmons, L.K.; Wang, X. The model of emissions of gases and aerosols from nature version 2.1 (MEGAN2.1): An extended and updated framework for modeling biogenic emissions. Geosci. Model Dev. 2012, 5, 1471-1492. [CrossRef]

31. Chen, F.; Dudhia, J. Coupling and advanced land surface-hydrology model with the Penn State-NCAR MM5 modeling system. Part I: Model implementation and sensitivity. Mon. Weather Rev. 2001, 129, 569-585. [CrossRef]

32. Hong, S.-Y.; Lim, J.J.-O. The WRF Single-Moment 6-Class Microphysics Scheme (WSM6). J. Korea Meteorol. Soc. 2006, $42,129-151$.

33. Holben, B.N.; Eck, T.F.; Slutsker, I.; Tanré, D.; Buis, J.P.; Setzer, A.; Vermote, E.; Reagan, J.A.; Kaufman, Y.J.; Nakajima, T.; et al. AERONET-A federated instrument network and data archive for aerosol characterization. Remote Sens. Environ. 1998, 66, 1-16. [CrossRef]

34. Malm, W.C.; Hand, J.L. An examination of the physical and optical properties of aerosols collected in the IMPROVE program. Atmos. Environ. 2007, 41, 3407-3427. [CrossRef]

35. Malm, W.C.; Day, D.E. Estimates of aerosol species scattering characteristics as a function of relative humidity. Atmos. Environ. 2001, 35, 2845-2860. [CrossRef]

36. Malm, W.C.; Pitchford, M.L.; Scruggs, M.; Sisler, J.F.; Ames, R.; Copeland, S.; Gebhart, K.A.; Day, D.E. IMPROVE III: Spatial and Seasonal Patterns and Temporal Variability of Haze and Its Constituents in the United States; Cooperative Institute for Research in the Atmosphere (CIRA), Colorado State University: Fort Coolins, CO, USA, 2000.

37. Duarte, R.M.B.O.; Santos, E.B.H.; Pio, C.A.; Duarte, A.C. Comparison of structural features of water-soluble organic matter from atmospheric aerosols with those of aquatic humic substances. Atmos. Environ. 2007, 41, 8100-8113. [CrossRef]

38. Lee, J.Y.; Jung, C.H.; Kim, Y.P. Estimation of optical properties for HULIS aerosols at Anmyeon Island, Korea. Atmosphere 2017, 8, 120. [CrossRef]

39. Graber, E.R.; Rudich, Y. Atmospheric HULIS: How humic-like are they? A comprehensive and critical review. Atmos. Chem. Phys. 2006, 6, 729-753. [CrossRef]

40. Han, K.M.; Jung, C.H.; Park, R.S.; Park, S.Y.; Lee, S.; Kulmala, M.; Petäjä, T.; Karasiński, G.; Sobolewski, P.; Yoon, Y.J.; et al. Data assimilation of AOD and estimation of surface particulate matters over the arctic. Appl. Sci. 2021, 11, 1959. [CrossRef]

41. Kiehl, J.T.; Schneider, T.L.; Rasch, P.J.; Barth, M.C.; Wong, J. Radiative forcing due to sulfate aerosols from simulations with the National Center for Atmospheric Research Community Climate Model, Version 3. J. Geophys. Res. Atmos. 2000, 105, 1441-1457. [CrossRef]

42. Kim, B.U.; Bae, C.; Kim, H.C.; Kim, E.; Kim, S. Spatially and chemically resolved source apportionment analysis: Case study of high particulate matter event. Atmos. Environ. 2017, 162, 55-70. [CrossRef]

43. Bae, C.; Kim, B.U.; Kim, H.C.; Yoo, C.; Kim, S. Long-range transport influence on key chemical components of PM2.5 in the Seoul metropolitan area, south korea, during the years 2012-2016. Atmosphere 2020, 11, 48. [CrossRef]

44. Yun, S.G.; Yoo, C. The effects of spring and winter blocking on PM10 concentration in Korea. Atmosphere 2019, 10, 410. [CrossRef]

45. Song, C.H.; Park, M.E.; Lee, K.H.; Ahn, H.J.; Lee, Y.; Kim, J.Y.; Han, K.M.; Kim, J.; Ghim, Y.S.; Kim, Y.J. An investigation into seasonal and regional aerosol characteristics in East Asia using model-predicted and remotely-sensed aerosol properties. Atmos. Chem. Phys. 2008, 8, 6627-6654. [CrossRef]

46. Park, R.S.; Song, C.H.; Han, K.M.; Park, M.E.; Lee, S.S.; Kim, S.B.; Shimizu, A. A study on the aerosol optical properties over East Asia using a combination of CMAQ-simulated aerosol optical properties and remote-sensing data via a data assimilation technique. Atmos. Chem. Phys. 2011, 11, 12275-12296. [CrossRef]

47. Kim, S.M.; Koo, J.H.; Lee, H.; Mok, J.; Choi, M.; Go, S.; Lee, S.; Cho, Y.; Hong, J.; Seo, S.; et al. Comparison of PM2.5 in Seoul, Korea estimated from the various ground-based and satellite AOD. Appl. Sci. 2021, 11, 10755. [CrossRef] 